\title{
Importance of environmental factors on plantings of wild- simulated American Ginseng
}

\author{
Karam C. Sheban (1D) David J. Woodbury $(\mathbb{D} \cdot$ Marlyse C. Duguid 10
}

Received: 14 July 2021/Accepted: 7 October 2021/Published online: 1 November 2021

(C) The Author(s) 2021

\begin{abstract}
American ginseng (Panax quinquefolius L.) is an herbaceous perennial plant native to the forests of eastern North America with a long history of use and harvest, and with a significant international market. To supply international demand, the plant is grown in the USA and Canada under artificial shade cloth. However, wild and wild-appearing ginseng roots command prices up to 100 times greater than roots cultivated in a field: \$550-2200 (US\$ dry kg) vs. \$20-70 (US\$ dry kg). Growing ginseng in a forested environment using a "wild-simulated" forest farming approach, where growers introduce ginseng into a forested environment and then let it grow with little to no intervention, allows forest farmers to access these higher prices and meet international demand. As climate change shifts growing conditions globally, there will be increasing opportunities for the forest farming of American ginseng internationally. In this study, we examined the main drivers of ginseng
\end{abstract}

Supplementary Information The online version contains supplementary material available at https://doi.org/10.1007/ s10457-021-00705-8.

K. C. Sheban $(\bowtie)$ D D. J. Woodbury · M. C. Duguid

Yale Forest School, Yale School of the Environment, 360

Prospect Street, New Haven, CT 06511, USA

e-mail: karam.sheban@yale.edu

D. J. Woodbury

e-mail: david.woodbury@yale.edu

M. C. Duguid

e-mail: marlyse.duguid@yale.edu growth and development in a wild-simulated ginseng forest farm. We measured the range of environmental conditions and built statistical models to examine which factors were most important for ginseng vigor. We found that the amount of sunlight, even under highly shaded conditions, was the most important driver of ginseng establishment on the landscape, as well as ginseng plant size and development. Prior research indicates that additional factors including soil nutrient levels, moisture, and texture are important for the survival, growth, and development of wild and planted American ginseng, but our study did not show significant patterns of importance at this site. Our findings suggest that integrating silvicultural techniques such as forest thinning may enhance the productivity of wild-simulated ginseng operations while providing additional forest-based income with minimal impact on natural forest ecosystems.

Keywords Forest farming - Agroforestry - Crops · Herbs · Understory · Groundstory · Non-timber forest products $\cdot$ NTFP

\section{Introduction}

American ginseng (Panax quinquefolius L.) is an herbaceous perennial plant native to the forests of eastern North America. Due to its medicinal properties 
and a strong demand for the plant in East Asia, it has been the focus of harvesting and exporting for over 300 years (Case et al. 2007). This harvest pressure has led to a declining abundance of the plant across its historic range, and to cultivation efforts to meet market demand (Case et al. 2007; Burkhart and Jacobson 2009). The majority of American ginseng supplied to the world market is produced through intensive cultivation methods, including soil tilling, erecting artificial cloth shade structures, and applying fertilizer and pesticides (OMAFRA-Ontario Ministry of Agriculture and Food 2009). The resulting monetary value of ginseng roots produced through intensive means, however, is significantly less than that of wild and wild-appearing roots-ginseng roots that display a high degree of heterogeneity in shape and size, in part a response to growing conditions in a forested environment-a result of Asian cultural tradition and preferences (Burkhart 2013). Exported to Asia, wild and wild-appearing roots can command prices up to 100 times greater than cultivated roots, with prices for cultivated root averaging \$20-70 (US\$ dry $\mathrm{kg}$ ) and prices for wild and wild-appearing roots averaging \$550-2,200 (US\$ dry kg) (Davis and Persons 2014; Burkhart 2013; Burkhart and Jacobson 2009).

Forest farming is an agroforestry practice used to cultivate a variety of non-timber forest products under a relatively in-tact forest canopy modified or maintained to favor growth and enhance production (Chamberlain et al. 2009). American ginseng is often a focus crop of forest farming systems across its native range, due to its suitability for forest-based production and the high prices paid for the resulting wildappearing roots (Nadeau et al. 1998; Burkhart 2013; Burkhart and Jacobson 2009). Within forest farming systems, ginseng can be cultivated using production methods that fall along a continuum ranging from a "woods-cultivated" approach (using a forest canopy to provide shade but making significant modifications to the growing environment, from tilling to pesticide and fertilizer application) to a "wild-simulated" approach (planting seeds in a forest environment and then allowing them to grow input-free under natural conditions; Chittum et al., 2019). In terms of number of ginseng growers worldwide, many opt for a wildsimulated approach as wild-simulated production requires the fewest chemical and labor inputs, incurs the lowest costs, entails minimal modification of the requisite forest environment, and produces roots of the highest value, with prices equaling that of wild ginseng (Carroll and Apsley 2013; Chittum et al. 2019).

In addition to specific advantages over field cultivation-lower costs and often higher price pointsthe forest farming of medicinal and culinary herbs using a wild-simulated production regime allows forest landowners to increase their land-based income while maintaining or even improving forest health and biodiversity (Hill and Buck 2000; Dix et al. 1997; Chittum et al. 2019). Forest farming has the additional advantage of restoring populations of ginseng on the landscape after centuries of wild harvest (Holmes and Matlack 2018; McGraw and Furedi 2005). The forest farming of American ginseng is already cosmopolitan, taking place across the eastern United States and Canada and in the deciduous forests regions of Northeast Asia (Hill, Buck, and Davis 2009; Xing, Guo, and Fu 2010; Bobev et al. 2003; Nadeau et al. 1998), and predictions suggest that a changing climate will increase suitable forested planting areas globally by $9.16-30.97 \%$, opening up new opportunities and expanding suitable habitat for the forest farming of American ginseng across Asia, Europe, and North America (Shen et al. 2019; Butler et al. 2015).

Like all agricultural operations, however, the profitability of a forest farming venture depends on the survival and growth of the crop. Using a wildsimulated production regime requires first identifying appropriate habitat; American ginseng thrives on cool, moist slopes under a deciduous canopy (CruseSanders and Hamrick 2004a, b). Land managers use environmental indicators such as slope and aspect as well as "indicator species"- species known to share an overlapping ecological niche with American ginseng-to determine good planting sites for wildsimulated ginseng (Apsley and Carroll 2013; Burkhart 2013; Turner and McGraw 2015). Yet the survival and vigor of wild-simulated ginseng populations often varies greatly across planting sites, despite the presence of indicator species, and as wild-simulated ginseng typically is not harvested for between 7-12 years the germination and long-term survival of wild-simulated populations is critical to the profitability of a forest farming venture (Turner and McGraw 2015). While forest vegetation is in part a reflection of the underlying environmental conditions on a particular site, indicator species can only serve as 
a proxy measure for the environmental factors influencing the establishment and development of American ginseng in a wild-simulated system (Gilliam 2014).

The relationship between the specific forested site conditions and the rates of establishment and development of wild-simulated ginseng plantings has not been as well studied or corroborated. There has been some research on the role that environmental factors such as soil moisture (Li and Berard 1998) and soil nutrients (Proctor and Shelp 2014) play in the survival and development of ginseng, suggesting that they are important. Perhaps the best studied soil nutrient in relation to plantings of ginseng is calcium, which studies have shown to play an important role in promoting ginseng survival, growth, and development (Beyfuss, 2000; Davis and Persons, 2014; Nadeau et al., 2003, 1998; Slak, 2005; Stoltz, 1982). And yet the results of recent research into the role of calcium in the development of wild and wild-simulated ginseng-as well as the use of indicator species to identify calcium-rich sites-has proven inconclusive (Burkhart 2013; Turner and McGraw 2015). Another important but understudied environmental factor is the role of light in the growth and development of ginseng (Chandler and McGraw 2015; Proctor and Palmer 2017; Wagner and McGraw 2013). Although ginseng is a shade-obligate species, research has shown conflicting effects of increased sunlight on its germination, survival, growth, and reproduction (Chandler and McGraw 2015; Li et al. 2000).

As wild-simulated ginseng production becomes an increasingly global endeavor-reducing the efficacy of a specific suite of indicator species in identifying appropriate planting sites-developing a better understanding of the relationship between the specific underlying environmental site conditions and the performance of plantings will be critical. To that end, this study examines the role of environmental conditions on the establishment and growth of ginseng under wild-simulated management. We measured ginseng establishment and growth in 59 plots in an active wild-simulated ginseng farm three years following direct seeding. At these plots we also measured a suite of environmental conditions important for plant development and examined the relationship between these environmental conditions and ginseng establishment and growth. Our results will help forest farmers better assess planting sites for maximizing ginseng productivity.

\section{Materials and methods}

Site description

We conducted this research on forestland owned and managed by American Ginseng Pharm (AGP), a wildsimulated American ginseng production forest in the Catskill region of New York, USA. The Catskill Mountains are located in Southeastern New York and constitute the northeastern end of the Appalachian Plateau. The climate is mountainous, with cold winters and moderately cool to warm summers, with an average annual temperature of $5{ }^{\circ} \mathrm{C}$. Heavy morning dew and fog are common in the spring, summer, and fall. Annual precipitation is around $150 \mathrm{~cm}$ (US Department of Commerce n.d.; Stoddard and Murdoch 1991). The soils are medium to moderately fine textured glacial till (USDA Soil Conservation Service 1985). The farm is a unique experimental agroforestry system with over 400 hectares of native northeast forestland managed for wild-simulated ginseng production, consisting of a series of parcels across a $182-\mathrm{km}$ range. The altitude range of planting sites is between 550 and 1,000 $\mathrm{m}$ above sea level. The large size of AGP land under wild-simulated ginseng production makes it a uniquely valuable site for observational research and data collection.

Each year beginning in July, AGP plants stratified American ginseng seed sourced from commercial ginseng farms in Quebec. The seeds are broadcast by hand at a rate between $12-40 \mathrm{~kg} / \mathrm{ha}$ and personnel at the farm are trained to broadcast $43-54$ seeds per square meter. To control for differences between years due to seasonal variation, we conducted this study on all areas planted by AGP in 2016, examining growth and establishment after three years. The total area planted in 2016 was 17.4 hectares distributed across 22 forest stands ranging in size from $0.03-0.79$ ha (Fig. 1).

\section{Experimental design}

Using the "Create Random Points" tool in ArcGIS, we randomly distributed 65 points across the designated study area. Ground-truthing revealed 59 of these 


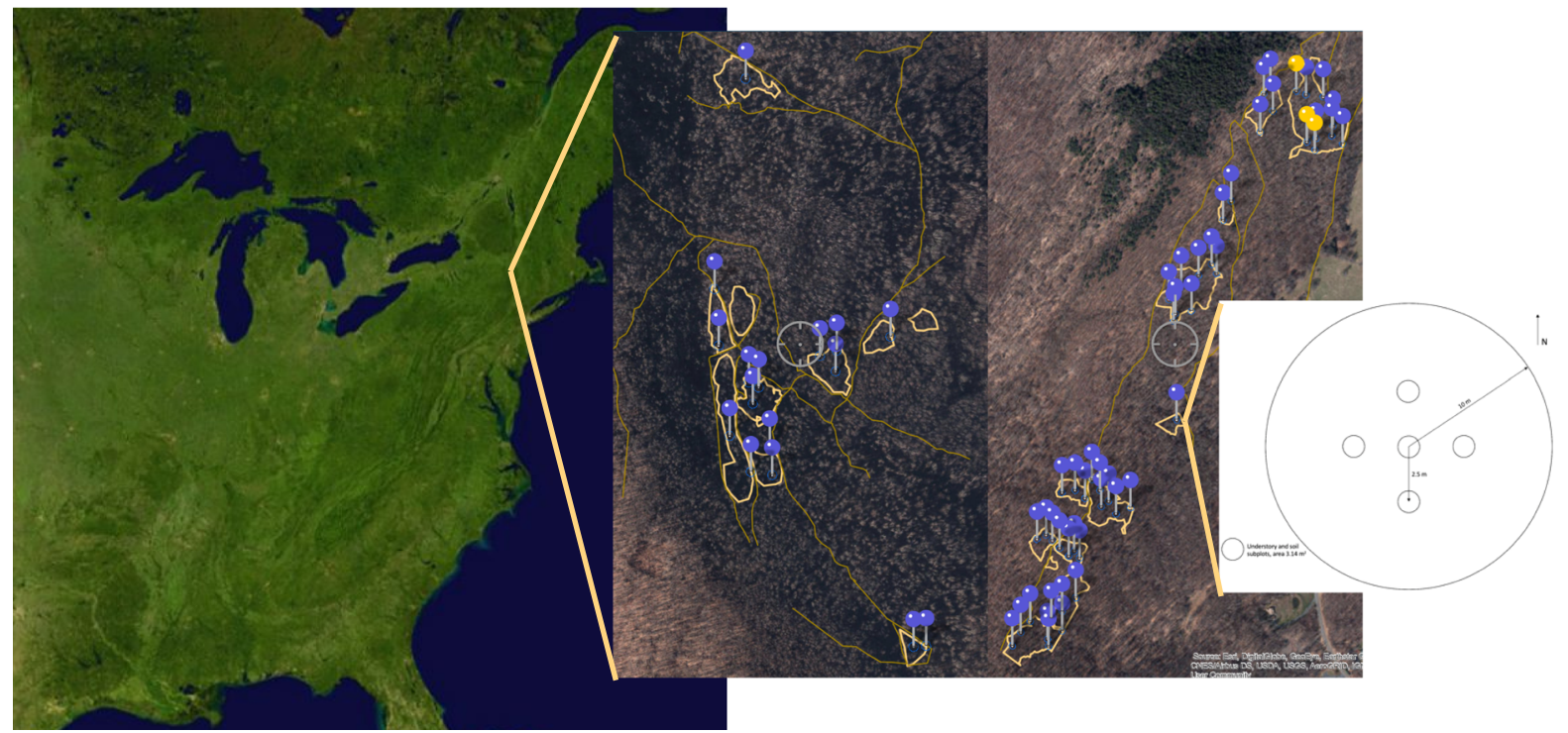

Fig. 1 Study site location in the Catskill Mountains of New York State, USA, with 2016 planting areas outline in yellow and plots marked with a purple pin (yellow pins indicate plots that

points to be suitable and within planting areas and were established as plots. Each of the 59 random points served as plot center for a round, $10 \mathrm{~m}$ radius $\left(314.16 \mathrm{~m}^{2}\right)$ fixed-area plot.

To assess canopy conditions we identified to species and measured every tree at diameter at breast height (dbh, greater than $5 \mathrm{~cm}$ at $1.3 \mathrm{~m}$ above the ground) within each $10-\mathrm{m}$ radius plot. We calculated basal area (BA) for each plot by adding the BA of each individual tree where $\mathrm{BA}$ in $\mathrm{m}^{2} / \mathrm{ha}=\mathrm{pi} *$ (tree diameter $(\mathrm{cm}) / 200)^{2} * 31.831$ (expansion factor). Per-tree basal area values were added to calculate total basal area per hectare on a per plot basis. Basal area as an easily calculated proxy variable for a variety of forest canopy traits, specifically tree density and competition (Brūmelis et al. 2020).

To examine ginseng vigor we set up five $1 \mathrm{~m}$ circular subplots within each plot, one at plot center and the remaining four three meters from plot center along cardinal directions (north, south, east, west; Fig. 1). In each of the five subplots we counted and measured every ginseng plant. To assess plant life stage, we counted the number of leaves, and to approximate root size, we measured the width of the central leaflet on the largest leaf of each individual ginseng plant. Prior research indicates that the square of the width of the central leaflet across ginseng were eliminated because ground truthing indicated they weren't suitable for the parameters of the study), and the plot design

species is an economical and accurate way to assess leaf area, which itself correlates with root size (Parmenter and Littlejohn 2000). As our methodology was designed to be replicated by forest farmers, measuring leaf size was both an accessible and nondestructive way to approximate the size of the merchantable underground ginseng roots.

In order to assess the degree of shade cover at each plot, we used a convex Forestry Suppliers Spherical Crown Concave Densiometer (Lemmon 1956). We took four measurements-facing north, east, south, and west-of canopy openness at each of the five subplots, for a total of twenty canopy measurements at each plot. These were averaged to provide one measurement of canopy openness per plot.

To examine the soils, we collected 15 twocentimeter diameter cores, 3 cores from each subplot. Each core began below the leaf litter at the Oa horizon and was $12 \mathrm{~cm}$ deep. The 15 cores were then passed through a four $\mathrm{mm}$ sieve and homogenized into a single composite sample, at the plot level. We air dried the soils for twelve weeks, then put them through a 2 -mm sieve. Soil texture was quantified with dispersion of soil particles using sodium hexametaphosphate followed by the (1) isolation of the sand fraction using a $0.053 \mathrm{~mm}$ sieve, and (2) separation of the silt and clay fractions by settling. Soil $\mathrm{pH}$ analysis was done 
using a modified Mehlich and Morgan Extraction, and percent soil organic matter (SOM) by mass loss on ignition (LOI) at $500{ }^{\circ} \mathrm{C}$ for $12 \mathrm{~h}$ (Ziadi and Tran 2008). The University of Connecticut's soil analysis lab conducted these analyses.

We quantified soil moisture in multiple ways. First, relative soil moisture was measured in situ as volumetric water content (VWC) using a handheld Hydrosense II Soil Water Content Measurement System (Campbell Scientific, Inc., Logan, UT, USA), with $12 \mathrm{~cm}$ rods. Three measurements were taken at each of the five subplots during an extended dry period of at least $72 \mathrm{~h}$. We conducted all VWC measurements within a two-day window to establish relative soil moisture across plots. Soil samples were used to calculate the water holding capacity of homogenized soils. Subsamples of fresh soil were used to measure field moisture content $\left(105{ }^{\circ} \mathrm{C}\right.$ for $24 \mathrm{~h}$ ) and water holding capacity (samples fully saturated, then drained for two hours, and dried at $105{ }^{\circ} \mathrm{C}$ for $24 \mathrm{~h}$ ) (Keiser 2016). We conducted all field measurements between June and July of 2019.

Data analyses

We used $\mathrm{R}$ statistical programming language version 3.6.2 (R Core Team, 2019) with the Rstudio platform version 1.2.5003 (RStudio Team, 2019) for all statistical analyses (Venables 2002).

Influence of seeding rate on ginseng plant density

Each of the 22 forest stands planted in 2016 were broadcast seeded at a different rate. The quantity of seed planted in each stand was recorded, in Imperial pounds of seed, by American Ginseng Pharm. Previous work indicates a pound of ginseng seed to contains 7,000 individual seeds (Carroll and Apsley 2013). We used this number, as well as the area dimensions of each stand, to calculate a seeding rate in seeds per $\mathrm{m}^{2}$ for each stand in our study. To test whether there was a relationship between seeding rate and plant density, we included the number of seeds planted in our final Generalized Linear Model, which examined the number of plants per square meter as the response variable. We also ran additional linear models examining the effect of the interaction between shade levels and the quantity of seed planted on the number of plants per square meter to further explore this relationship. In order to better understand the relationship between seeding rate and the density of ginseng plants present three years after planting, we ran a linear model, using the R package "Interactions" (Long 2019), on the interaction between shade and seeding rate with log-transformed plant density as our response variable. Plant density was log-transformed in order to meet assumptions of normality.

Influence of forest structure and environmental conditions on ginseng growth and vigor

We used an a priori variable selection for our models. To identify collinear variables, we used a correlation matrix, produced using corrplot() in the corrplot package in R (Wei and Simko 2017) to identify any highly correlated variables ( $>50 \%$; see Fig. S1). We also used Principle Components Analysis (PCA) using the "princomp" function in the stats package (R Core Team 2019) to assess the relative importance of variables to each component. When variables were correlated (e.g., pH and Calcium) we selected the variable based on importance in the literature for the establishment and development of American ginseng and ease of measuring in the field for use in our models. We then combined the results of the correlation matrix between predictor variables and the results of the PCA with the literature on important limits to ginseng growth to reach a final list of predictor variables for inclusion in our regression models: canopy cover, kilograms of calcium per hectare, water holding capacity, trees per hectare, and basal area.

We ran three Linear Mixed Effects Models using the lmer() function in the lme4 package (Bates et al. 2015) assuming a Gaussian distribution for all models after testing for homoscedasticity of variance and for the normality of residuals. Using the list of final predictor variables mentioned above, our response variables were: 1) log-transformed number of ginseng plants, 2) number of leaves, and 3) average center leaflet width. While the center leaflet width can be squared to approximate the area of the center leaflet, and a leaflet size ratio can be used to estimate the area of the other leaflets and therefore the plant's total leaf surface area, we were interested in relative differences between our plots so we ran our analyses using the raw width measurement (Parmenter \& Littlejohn, 2000). We checked that models fit assumptions using the "qqnorm" function in the stats package (R Core Team 
2019), and we also checked the Variance Inflation Factor (VIF) for each of our models to ensure they were not overfit, with the highest VIF value being 1.74 indicating no multicollinearity in our models.

\section{Results and discussion}

A generalized description for the development of ginseng over time has the plant emerge in its first year of growth as a trifoliate seedling, with three small leaflets. In its second year of growth the plant adds two additional leaflets to its single leaf, presenting as a palmately compound leaf with five leaflets. During years 3-6 the plant will add an additional palmately compound leaf with five leaflets, and after year 6 may add a third or even fourth leaf (Anderson et al., 2002).

Influence of the interaction between shade and seeding rate on ginseng plant density

Our plots, three years old, contained an average of 49 ginseng plants $(s d=37.732)$, for an average plant density of 3.13 ginseng plants per square meter. Ginseng plants had an average of 0.42 leaves $(s d=0.230$ ), on a scale from 0 (representing the trifoliate seedling stage) to 3 (the highest number of leaves observed), meaning they averaged between a seedling stage and a single-leafed plant (see Table S1 in supplemental materials). All of our plots were quite shady (\% shade $\underline{X}=92.2 ; s d=1.91$ ) and our analysis indicates a significant positive relationship between the interaction of shade and seeding rate on plant density (Fig. 2, overall model $\mathrm{r}^{2}=0.18, \mathrm{p}<0.001$ ). As shade levels increase from 88 to $96 \%$ the marginal benefit of seeding at a higher density decreases until at about $95 \%$ canopy shade coverage, where there is no longer any increase in plant density attributable to an increase in seeding rate (Fig. 2). Conversely, as plots become sunnier, planting a higher quantity of ginseng seed resulted in a higher plant density in our 3-year-old plantings. This would corroborate the experience of American Ginseng Pharm General Manager, Anna Plattner, namely that "seeding heavier gives you more plants on your good sites but just as few plants on your bad sites" (Anna Plattner, personal communication). Prior research has suggested that optimal plant spacing is 20 plants per square meter, or approximately two plants per square foot ( $\mathrm{Li}$ 1995). To achieve this plant density, both research and present practice recommends seeding at a rate of 43-54 seeds per square meter, or 4-5 seeds per square foot (Carroll and Apsley 2013). Across the plots we measured, the seeding rate ranged from $21-70$ seeds per square meter, or approximately 2-6.5 seeds per square foot $(\underline{X}=38.056$ seeds per square meter, $s d=10.529)$. In controlled studies, over-sowing of ginseng seed has been shown to decrease plant emergence and root size (Mo et al. 2014), while the clustering of plants in wild populations - though it may simply reflect dispersal limitations (Cruse-Sanders and Hamrick 2004a, b) could also suggest that ginseng plants are responding positively to favorable microsite conditions (Wagner and McGraw 2013; Wulfsberg 2019). Given that our plots exhibited a relatively narrow range of shade conditions, it is unclear whether the increasing positive effect of seeding density on plant density with decreasing shade levels would continue under sunnier conditions. However, our findings do suggest that on shadier sites, an increase in seeding rate beyond the 43-54 per square meter recommended in the literature would not result in a greater plant density after three years.

It should be noted that the seed planted at our study site was sourced from field-cultivated commercial operations located in Quebec (Anna Plattner, personal communication). These commercial operations, concentrated in Ontario, Canada, and in the state of Wisconsin in the United States, constitute the source of much of the ginseng seed used in forest farming operations (Burkhart et al., 2021). There is debate over whether introducing non-local genetics-from plants cultivated in a highly controlled, industrial environment - could result in ginseng plantings maladapted to local conditions (Burkhart et al., 2021; Schlag \& McIntosh, 2012; Schluter \& Punja, 2002). It is possible that plants with local genetics may have responded differently to environmental variables on our research sites, but as many forest farmers source their seed from commercial operations we feel our results reflect the planting and plant sourcing conditions most representative of the current active forest farming community (Burkhart et al., 2021). 


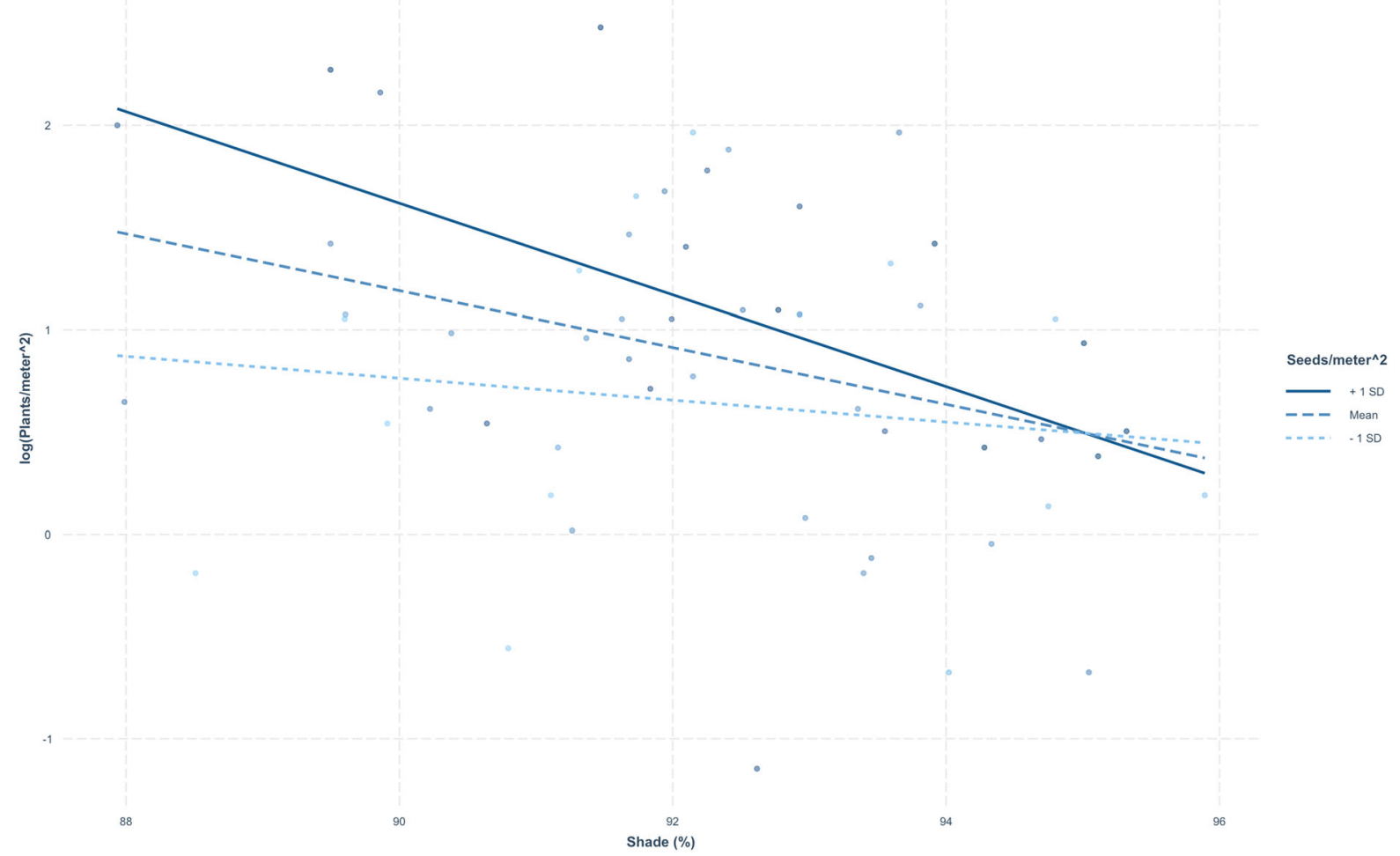

Fig. 2 This interaction plot illustrates the effect of shade levels on ginseng plant density three years after the seeds were planting with varying seeding rates. The three trend lines indicate three different levels of seeding: the center, medium blue hashed line represents the mean seeding rate across all our plots, while the top, dark blue solid line represents one standard deviation above

Influence of forest structure and environmental conditions on ginseng growth and vigor

Results from our regression models show that the effects of environmental conditions do not equally influence ginseng response variables. Our models had the most predictive power when considering the number of ginseng plants, followed by the size of ginseng plants, and lastly the number of ginseng leaves (maturity). We found that across all our analyses, shade levels had the strongest and most persistent effect on ginseng performance (Table 1). For the number of plants, our model had an overall $\mathrm{r}^{2}$ of 0.451 , with fixed effects contributing 0.295 and random effects an additional 0.156 to the total variance explained. The most important-in fact, the only significant-variable was shade. For the number of leaves, our model had an $r^{2}$ of 0.157 , with random effects having a negligible contribution to the variance the mean seeding rate and the bottom, light blue hashed line represents on standard deviation below the mean seeding rate. The convergence of these lines at higher levels of shade suggests that as shade levels increase above 95\%, planting higher densities of ginseng seed no longer provides a subsequent increase in the number of ginseng plants

explained. Again, shade was the only variable in the model making a significant contribution. For the average leaf width, our model had an $\mathrm{r}^{2}$ of 0.366 , with fixed effects contributing 0.312 and random effects an additional 0.054 to the total variance explained. Shade made the only significant contribution to this model as well (Table. 2).

Our models showed a clear and consistent relationship between the amount of light present in our plots and each of our three response variables indicating ginseng establishment, growth, and vigor. The production recommendations for commercial ginseng growers, using artificial shade structures, suggest the creation of a light environment between 74-82\% shade (Ontario Ministry of Agriculture 2001), while present practice among wild-simulated and woodscultivated growers is to simply use the shade conditions found in American ginseng's native eastern deciduous forest environment, namely between 70 and 
Table 1 The results from our Generalized Linear Mixed Effects Models (GLMs). The table shows the results of three models, for three response variables: Ginseng plant density (logged to meet assumptions of normality), ginseng leaflet width, and number of ginseng leaves. The predictor variables are shade levels, $\mathrm{pH}$, water holding capacity (WHC), tree density (trees.ha), and tree basal area, as well as the density of

\begin{tabular}{|c|c|c|c|c|c|c|c|c|c|}
\hline \multirow[t]{2}{*}{ Predictors } & \multicolumn{3}{|c|}{$\log ($ Plants.meter $)$} & \multicolumn{3}{|l|}{ Width } & \multicolumn{3}{|l|}{ Leaves } \\
\hline & Estimates & $\mathrm{CI}$ & $P$ & Estimates & $\mathrm{CI}$ & $P$ & Estimates & $\mathrm{CI}$ & $P$ \\
\hline (Intercept) & 19.16 & $9.12-29.21$ & $<0.001$ & 11.92 & $6.77-17.07$ & $<0.001$ & 4.69 & $1.27-8.11$ & 0.008 \\
\hline Shade & -0.19 & $\begin{array}{l}-0.29 \\
\text { to }-0.08\end{array}$ & $<0.001$ & -0.10 & $\begin{array}{l}0.15 \\
\quad \text { to }-0.05\end{array}$ & $<0.001$ & -0.04 & $\begin{array}{l}-0.08 \\
\text { to }-0.01\end{array}$ & 0.016 \\
\hline $\mathrm{pH}$ & -0.50 & $-1.19-0.19$ & 0.154 & 0.06 & $-0.26-0.38$ & 0.716 & -0.03 & $-0.23-0.17$ & 0.758 \\
\hline WHC & 0.01 & $-0.03-0.04$ & 0.714 & -0.01 & $-0.03-0.01$ & 0.311 & -0.00 & $-0.01-0.01$ & 0.769 \\
\hline Seeds.meter & 0.00 & $0.00-0.00$ & 0.048 & -0.00 & $-0.00-0.00$ & 0.227 & -0.00 & $-0.00-0.00$ & 0.552 \\
\hline Trees.ha & -0.02 & $-0.05-0.00$ & 0.102 & 0.00 & $-0.01-0.01$ & 0.963 & -0.00 & $-0.01-0.00$ & 0.394 \\
\hline Basal.area & -0.02 & $-0.05-0.00$ & 0.102 & 0.00 & $-0.01-0.01$ & 0.963 & -0.00 & $-0.01-0.00$ & 0.394 \\
\hline \multicolumn{10}{|l|}{$\begin{array}{l}\text { Random } \\
\text { Effects }\end{array}$} \\
\hline$\sigma^{2}$ & 0.36 & & & 0.11 & & & & & \\
\hline$\tau^{2}$ & $\begin{array}{l}0.12 \\
\text { Stand }\end{array}$ & & & 0.01 Stand & & & & & \\
\hline ICC & 0.25 & & & 0.09 & & & & & \\
\hline $\mathrm{N}$ & 21 Stand & & & 21Stand & & & & & \\
\hline Observations & 59 & & & 59 & & 59 & & & \\
\hline $\begin{array}{l}\mathrm{R}^{2} \\
\quad \text { (model/fixed/ } \\
\text { random) }\end{array}$ & $\begin{array}{c}0.451 / \\
0.295 / \\
0.156\end{array}$ & & & $\begin{array}{c}0.157 / \\
0.157 / \\
0.00\end{array}$ & & $\begin{array}{c}0.366 / \\
0.312 / \\
0.054\end{array}$ & & & \\
\hline
\end{tabular}

seeds planted only for the response variable of ginseng plant density. Random effects values only appear for response variables ginseng plant density and leaflet width because they were negligible for the number of ginseng leaves. The $r 2$ values at the bottom show the contribution of fixed and random effects to the overall explanatory power of the models
90\% shade coverage (Proctor and Palmer 2017; Proctor et al. 1988). These numbers should be understood in relation to the scholarship on light and understory plants. Though there is variation across forest types and understory species, the literature has shown a positive relationship between sunfleck size, intensity, and duration and the carbon gain, growth, and reproductive potential of understory plants (Chazdon, 1988; Chazdon \& Pearcy, 1991; Neufeld \& Young, 2014; Pearcy \& Pfitsch, 1995). However, receiving direct irradiance in the form of sunfleckswhich can increase the photon flux density (PFD) two orders of magnitude in a matter of seconds (Chazdon, 1988)_induces high level of physiological stress, and during exposure to the more direct sunlight of a sunfleck photosynthesis may be limited by high leaf temperatures and transpiration rates, which can cause permanent heat damage, stomatal closure, and wilting (Chazdon \& Pearcy, 1991; Rackham, 1975;
Woodward, 1981; Young \& Smith, 1979). Efficiency of sunfleck use and tolerance to the potentially damaging effects of direct sunlight during prolonged exposure vary both between understory species as well as within a given species during different phases of growth and under differing site conditions (Chazdon, 1988; Chazdon \& Pearcy, 1991). The research on the relationship between light availability and plant growth for understory species that co-occur with American ginseng in the Eastern United States has been mixed. Dion et al. (2017) found that greater light levels reaching the forest floor during the growing season-due to a forest canopy composed of species with late-season budburst-led to higher levels of growth in transplanted forest populations of Allium triccocum. Meanwhile, Sanders and McGraw (2005) found no relationship between light levels and growth of transplanted forest populations of Hydrastis canadensis, though higher light levels did correlate 
with smaller leaf area. Research on the effect of high light levels on Panax ginseng has shown that they cause photoinhibition, reduced leaf size, and early senescence, while also resulting in higher rates of photosynthesis, leaving somewhat open the question of whether a high light environment leads to faster growth rates (Parmenter \& Littlejohn, 1998, 2000).

More recent research has suggested that American ginseng growth rates are positively associated with greater light from sunflecks-though seed germination was found to be negatively associated with increased light—and that an increased light environment resulting from timber harvesting can lead to these increased growth rates (Chandler and McGraw 2015; Wagner and McGraw 2013). Drawing from these studies indicating that ginseng may benefit from a higher light environment, Proctor and Palmer (2017) sought to establish, for the first time, the optimal light requirements for ginseng seedlings grown in greenhouses. They found that the optimal shade level for growth was $65.4 \%$. This study, however, took place in a highly controlled environment and only examined plants in their first year of growth. The authors noted that the optimal light level for growing ginseng is determined by a "combination of plant responses to light, and the associated specific environmental and plant health issues at that location."

One notable feature of our study site was its high degree of shade. Trees per hectare averaged 427 $(s d=124)$, while basal area averaged $28.7 \mathrm{~m}^{2}$ per hectare $(s d=7.95)$. Across the plots we measured, shade levels ranged from 87.9 to $95.9 \%(X=92.3$, median $=92.1, \quad \mathrm{sd}=1.9)$, in comparison to the 70-90\% considered "natural" in Eastern deciduous mature, closed canopy forests (Proctor and Palmer 2017). Across all of our analyses, the degree of shade cover had a persistent, negative relationship with number of ginseng plants, maturity of ginseng plants, and width of ginseng leaves (Fig. 3). The strength of these relationships, and their statistical significance suggest that sunlight was operating as the limiting environmental factor in the establishment, growth, and development of ginseng plantings in comparison to the other environmental variables in our study site. This finding suggests an opportunity for forest farmers to implement silvicultural techniques to provide additional sunlight in the understory, which has been shown to have a positive effect on ginseng growth
(Chamberlain et al. 2018; Chandler and McGraw 2015; Fournier et al. 2008, 2004).

While greenhouse research has indicated that optimal light levels for ginseng seedlings could be as low as $65.4 \%$, in a wild-simulated forest environment increased light from canopy gaps could lead to greater interspecies competition with ginseng plantings in the understory (Beckage et al. 2011). Additionally, the uniform quality of light coming through shade cloth is different than the more variable light environment of a forest, where understory plants have evolved physiological mechanisms to respond to sunflecks (Chazdon and Pearcy 1991; Wagner and McGraw 2013). More experimentation in wild-simulated ginseng plantings is necessary to identify the optimal light levels for stimulating ginseng growth in a natural forest environment while maintaining relatively low levels of interspecies competition. However, utilizing silviculture that minimizes forest floor disturbance and mimics old-growth canopy structure to produce a timber crop within wild-simulated ginseng plantings has the potential to improve the value of a ginseng crop while creating an additional revenue stream from timber (Chandler and McGraw 2015; Peever 2004).

The role of soil characteristics on Ginseng growth

On the whole, the soils in our study site were very acidic ( $\mathrm{pH} \underline{X}=4.01, \mathrm{sd}=0.32$ ), Soil texture is a loam, averaging $47.6 \%$ sand $(s d=6.44), 14.6 \%$ clay $(s d=$ $3.55)$, and $37.9 \%$ silt $(s d=4.45)$. Soils had moderate levels of calcium and potassium averaging $1530 \mathrm{~kg} / \mathrm{ha}$ $(s d=943)$ and $154 \mathrm{~kg} / \mathrm{ha}(s d=43.6)$ respectively, and high levels of aluminum (aluminum ppm $\underline{X}=$ 118.95, sd = 54.39). Our results showed that levels of calcium and aluminum were highly negatively correlated in our plots (Pearson correlation coefficient = 0.76; Fig. S1). Meanwhile, calcium had a significant but only slight positive relationship with average ginseng center leaflet width (Coefficient $=0.00013$, $\left.\mathrm{r}^{2}=0.0805, \mathrm{p}<0.05\right)$, while it had no significant relationship with either the number or maturity of ginseng plants. The relationship between calcium and aluminum in acidic forest soils is well understood (Rengel 1992). While visible signs of aluminum toxicity were not observed in the field, aside from small size of the three-year-old ginseng plants in many plots, prior research in wild-simulated forest plantings of American ginseng in highly acidic soils has shown 

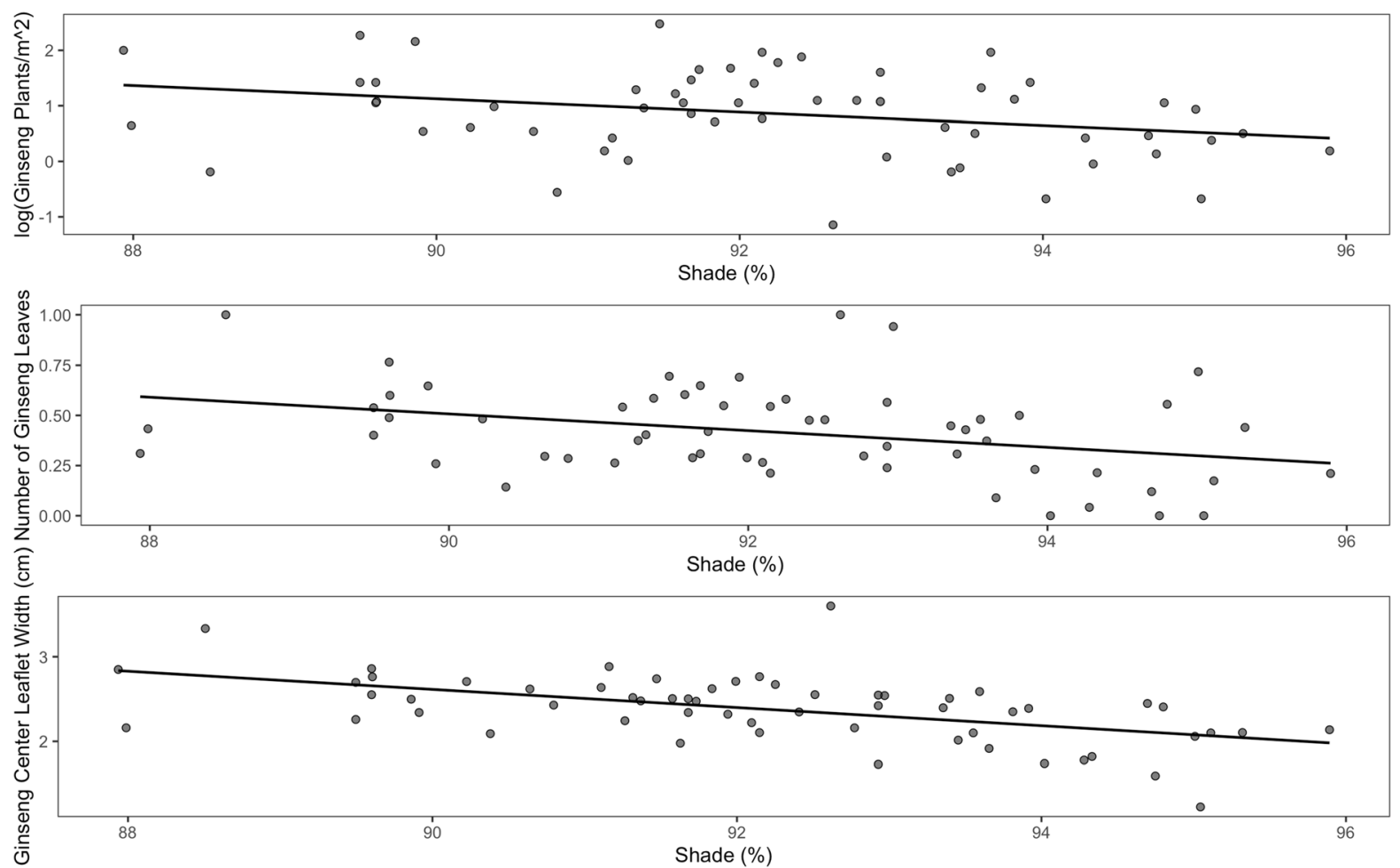

Fig. 3 Linear relationships between response variables and shade, to illustrate the effect of shade in our models. A Impact of shade on the log of ginseng plant density. B Impact of shade on the average number of ginseng leaves per plant. $\mathbf{C}$ Impact of

that increasing calcium levels and raising soil $\mathrm{pH}$ through the application of lime (calcium oxide) both lowers soil Aluminum levels and increases ginseng leaf area, as well as plant emergence, survival, and shoot and root mass (Nadeau et al. 2003; Nadeau et al. 1998; Olivier et al. 2005; Peever 2004). Given that our data did not reveal a meaningful relationship between these soil properties and ginseng performance, we can draw two conclusions with management implications for wild-simulated ginseng growers who have more marginal planting sites: 1) on the one hand, our study shows that it is indeed possible to grow ginseng without soil amendments on acidic soils that exhibit a range of soil calcium and aluminum levels, and 2) on the other hand, it is also possible that the ginseng plants across our study sites would have experienced a boost in performance through the practice of liming.

This relationship between calcium and ginseng performance is well documented in the literature. Stoltz (1982) found that the withholding of calcium led to slower growth and earlier foliar deficiency shade on the average width of the central leaflet. The graphs illustrate a consistent relationship found between shade and ginseng performance in our study: as light levels decrease, ginseng plants become less numerous, smaller, and less mature

symptoms than when $\mathrm{N}, \mathrm{P}$, or $\mathrm{Mg}$ were withheld. In wild-simulated research trials, it has been found that adding calcium by liming the soil resulted in improved ginseng survival and growth (Nadeau et al. 2003; Nadeau et al. 1998; Slak 2005). Research by Robert Beyfuss (2000) suggested that sites with the highest levels of calcium produced the largest ginseng roots. And calcium is also known to decrease aluminum toxicity, which is a major limiting factor for plant growth and crop production in strongly acidic soils (Foy 1992; Nadeau et al. 1998). Building off of Beyfuss (2000) and Persons and Davis (2014), Burkhart (2013) identified a threshold of 3,360 kg/ha for identifying promising sites for planting ginseng. In spite of these prior findings, and given that our sites were quite acidic, our data did not indicate that calcium had a major role in determining plant size, survival, or maturity. 
Conclusions and future research

In this study, we examined the relationships between a range of environmental conditions and plantings of wild-simulated American ginseng in an observational study on an active ginseng farm. Because this study was not a designed experiment there are some limitations. First, while we had an overall seeding rate per stand, given the heterogeneity of the planting sites sampled in our study (with boulders, fallen trees, ephemeral streams, etc.) seeds could not be broadcasted evenly across the landscape. This meant that we could not directly calculate measures such as survival or establishment, and instead could only determine relative success. We attempted to compensate for these challenges by incorporating random effects into our models and eliminating plots where it was clear that no seeds had been planted, but future work seeking to address similar questions could set up controlled germination studies to generate findings of greater specificity. Second, as our plots were all located on sites deemed appropriate for planting by AGP, the variability across our sites was not very high for some of the environmental variables we measured. Shade levels varied between 87 and $96 \%$ across our plots, while $\mathrm{pH}$ varied between 3.6 and 5.2, to take two examples. This lack of variability likely obscured the full depth of the relationships between our environmental and ginseng response variables. Taking measurements in wild-simulated plantings of ginseng across a greater range of site conditions would provide a fuller picture of these relationships. Overall, we feel that the benefits of doing these studies on active farms outweighs the limitations and provide important data for farmers by examining what is currently working in the field and therefore suggest that future work should include both carefully controlled experiments along with observational studies to better understand the mechanisms at play in these systems.

Our results suggest that a mature, closed canopy forest may require silvicultural thinning in order to maximize ginseng performance. While wild-simulated ginseng production is by definition a hands-off approach to the forest cultivation of ginseng, the clearing of ferns, brush, and small diameter trees falls under the purview of the practice. A light thinning of trees in areas devoted to wild-simulated production could provide additional opportunities for sustainable income generation in the form of wood products or additional non-timber products such as mushrooms produced from inoculated logs. Further research is needed to determine whether it is preferable to remove canopy trees or understory trees to create additional sunlight. And although laboratory research indicates that ginseng seedlings may grow the fastest under $65.4 \%$ shade, introducing significant light to the understory in a forest would likely lead to greater levels of competition (Proctor and Palmer 2017). Thus, forest-based research is needed to determine the optimal level of sunlight that balances ginseng survival, growth, and development with inter-species competition. Additionally, follow-up research on the interaction between light levels and seeding rate and the subsequent effect on establishment could help forest farmers decide how much seed to plant on a given site, and whether that decision should be influenced by light levels and a desire (or lack thereof) to modify the light environment via thinning.

Our study also found that it is possible to cultivate ginseng on highly acidic sites with lower levels of calcium and higher levels of aluminum that the literature has identified as optimal. This is not a given-Olivier et al (2005) found that five years after planting ginseng on acidic sites in Canada, their control plots (no modifications) had no ginseng plants that survived. Our study leaves open the possibility that modifying calcium levels on highly acidic soils, through the application of lime, could result in a higher $\mathrm{pH}$ and increased performance of ginseng plantings. As the wild-simulated cultivation of American ginseng becomes increasingly global, our findings suggest that forest farmers interested in the productivity and profit potential of their operations should consider not only using indicator species to identify planting sites, but investing in handheld tools such as a densiometer and a $\mathrm{pH}$ meter. And they should consider site modifications such as thinning and lime application viable strategies for increasing the performance of wild-simulated ginseng plantings on shaded and acidic sites.

Acknowledgements We would like to acknowledge that this research took place on the homelands of the Mohican and Haudenosaunee peoples. Before it was a commodity crop, ginseng was used by Indigenous peoples for thousands of years, and much of what we know about the plant originates from this Indigenous knowledge, which in many cases was stolen and repackaged without attribution. This research was funded by USDA's Northeast Sustainable Agriculture Research and 
Education (SARE) Graduate Student grants program, and Yale University's School of the Environment Berkley Conservation Scholarship. We would like to thank American Ginseng Pharm, specifically Anna Plattner and Justin Wexler for letting us access their land, help with navigation in the field, and support through subsequent stages of the research process. Thank you to Dr. Mark Ashton and his lab group for feedback and comments on this project. We would like to thank Schuyler Borden, Sophie Boehm, and Jonathan Reuning-Scherer for support and feedback on data analysis. And to Tanner Filyaw and Dr. Eric Burkhart-without their immense knowledge on American ginseng and generosity over many conversations this project likely would not have happened.

Author contributions KCS and MCD conceived of the project idea. KCS planned and implemented soil and vegetation sampling. KCS and DJW analyzed and interpreted data. KCS wrote the original manuscript, with contributions from all authors.

Funding This project was made possible through funding provided by the USDA's Northeast Sustainable Agriculture Research and Education (SARE) Graduate Student grants program, as well as funding through Yale University's School of the Environment Berkeley Conservation Scholarship.

Data availability Data will be uploaded to DRYAD on acceptance of this manuscript.

\section{Declarations}

Conflict of interest We have no conflicts of interest to disclose.

Open Access This article is licensed under a Creative Commons Attribution 4.0 International License, which permits use, sharing, adaptation, distribution and reproduction in any medium or format, as long as you give appropriate credit to the original author(s) and the source, provide a link to the Creative Commons licence, and indicate if changes were made. The images or other third party material in this article are included in the article's Creative Commons licence, unless indicated otherwise in a credit line to the material. If material is not included in the article's Creative Commons licence and your intended use is not permitted by statutory regulation or exceeds the permitted use, you will need to obtain permission directly from the copyright holder. To view a copy of this licence, visit http://creativecommons.org/licenses/by/4.0/.

\section{References}

Anderson RC, Anderson MR, Houseman G (2002) Wild American Ginseng. Nat Plants J 3(2):93-105

Bates D, Maechler M, Bolker B, Walker S (2015) Fitting linear mixed-effects models using $\{1 \mathrm{lme} 4\}$. J Stat Softw 67(1): $1-48$
Beckage B, Clark JS, Clinton BD, Haines BL (2011) A longterm study of tree seedling recruitment in southern Appalachian forests: the effects of canopy gaps and shrub understories. Can J Res. https://doi.org/10.1139/x00-075

Beyfuss R (2000) Soil nutrient characteristics of wild ginseng populations in New York, New Jersey, Maine, and Tennessee. In: Proceedings of the " "American Ginseng Production in the 21st Century"' Conference, pp 105-114

Bobev SG, Baeyen S, Crepel C, Maes M (2003) First Report of Phytophthora cactorum on American Ginseng (Panax quinquefolius) in Bulgaria. Plant Dis 87(6):752-752. https://doi.org/10.1094/PDIS.2003.87.6.752C

Brūmelis G, Dauškane I, Elferts D, Strode L, Krama T, Krams I (2020) Estimates of tree canopy closure and Basal Area as Proxies for Tree Crown volume at a stand scale. Forests 11(11):1180. https://doi.org/10.3390/f11111180

Burkhart EP, Nilson SE, Pugh CV, Zuiderveen GH (2021) Neither Wild nor Cultivated: American Ginseng (Panax quinquefolius L.) Seller Surveys Provide Insights into in situ Planting and Husbandry1. Econ Bot 2:10. https:// doi.org/10.1007/s12231-021-09521-8

Burkhart EP (2013) American ginseng (Panax quinquefolius L.) floristic associations in Pennsylvania: guidance for identifying calcium-rich forest farming sites. Agrofor Syst. https://doi.org/10.1007/s10457-013-9627-8

Burkhart EP, Jacobson MG (2009) Transitioning from wild collection to forest cultivation of indigenous medicinal forest plants in eastern North America is constrained by lack of profitability. Agrofor Syst 76(2):437-453. https:// doi.org/10.1007/s10457-008-9173-y

Butler PR, Iverson L, Thompson FR, Brandt L, Handler S, Janowiak M, Shannon PD, Swanston C, Karriker K, Bartig J, Connolly S, Dijak W, Bearer S, Blatt S, Brandon A, Byers E, Coon C, Culbreth T, Daly J, Zegre N (2015) Central Appalachians forest ecosystem vulnerability assessment and synthesis: a report from the Central Appalachians Climate Change Response Framework project (NRS-GTR-146; p. NRS-GTR-146). U.S. Department of Agriculture, Forest Service, Northern Research Station. https://doi.org/10.2737/NRS-GTR-146

Carroll C, Apsley D (2013) Growing American Ginseng in Ohio: An Introduction. Ohio State University. https:// woodlandstewards.osu.edu/sites/woodlands/files/d6/files/ pubfiles/0056\%20-\%20ginseng\%20intro.pdf

Case MA, Flinn KM, Jancaitis J, Alley A, Paxton A (2007) Declining abundance of American ginseng (Panax quinquefolius L.) documented by herbarium specimens. Biol Conserv 134(1):22-30. https://doi.org/10.1016/j.biocon. 2006.07.018

Chamberlain JL, Davis J, Duguid M, Ellum D, Farrell M, Friday JB, Fuller D, Kruger S, Marcano-Vega H, McCoy JA, Page D, Prisley S, Young J, Zasada J (2018) Nontimber forest products and production. In Assessment of nontimber forest products in the United States under changing conditions, pp. 10-57. Department of Agriculture, Forest Service, Southern Research Station https://www.fs.usda. gov/treesearch/pubs/all/57296

Chamberlain JL, Mitchell D, Brigham T, Hobby T, Zabek L, Davis J (2009) Forest farming practices. In: North American agroforestry: an integrated science and practice, 
pp 219-255. Wiley. https://doi.org/10.2134/2009. northamericanagroforestry.2ed.c9

Chandler JL, McGraw JB (2015) Variable effects of timber harvest on the survival, growth, and reproduction of American ginseng (Panax quinquefolius L.). For Ecol Manag 344:1-9. https://doi.org/10.1016/j.foreco.2015.02. 007

Chazdon RL (1988) Sunflecks and their importance to forest understorey plants. In: Begon M, Fitter AH, Ford ED, Macfadyen A (eds) Advances in ecological research. Academic Press, London, pp 1-63. https://doi.org/10.1016/ S0065-2504(08)60179-8

Chazdon RL, Pearcy RW (1991) The importance of sunflecks for forest understory plants. Bioscience 41(11):760-766

Chittum HK, Burkhart EP, Munsell JF, Kruger SD (2019) A Pathway to a Sustainable Supply of Forest Herbs in the Eastern United States. HerbalGram J Am Bot Counc 124:60-77

Cruse-Sanders JM, Hamrick JL (2004a) Genetic diversity in harvested and protected populations of wild American ginseng, Panax quinquefolius L. (Araliaceae). Am J Bot 91(4):540-548. https://doi.org/10.3732/ajb.91.4.540

Cruse-Sanders JM, Hamrick JL (2004b) Spatial and Genetic Structure within Populations of Wild American Ginseng (Panax quinquefolius L., Araliaceae). J Hered 95(4):309-321. https://doi.org/10.1093/jhered/esh046

Dion PP, Bussières J, Lapointe L (2017) Late canopy closure delays senescence and promotes growth of the spring ephemeral wild leek (Allium tricoccum). Bot 95(5):457-467. https://doi.org/10.1139/cjb-2016-0317

Dix ME, Hill DB, Buck LE, Rietveld WJ (1997) Forest farming: an agroforestry practice (Notes 7; Agroforestry Notes (USDA-NAC), p. 5). U.S. Department of Agriculture, Forest Service, National Agroforestry Center. https:// digitalcommons.unl.edu/agroforestnotes/5/

Fournier AR, Gosselin A, Proctor J, Gauthier L, Khanizadeh S, Dorais M (2004) Relationship between Understory Light and Growth of Forest-grown American Ginseng (Panax quinquefolius L.). J Am Soc Hortic Sci 129:425-432. https://doi.org/10.21273/JASHS.129.3.0425

Fournier ARTAJ, Khanizadeh S, Gosselin A, Dorais M (2008) Acclimation of maximum quantum yield of PSII and photosynthetic pigments of Panax quinquefolius L. to understory light. J Ginseng Res 32(4):347-356. https://doi. org/10.5142/JGR.2008.32.4.347

Foy CD (1992) Soil chemical factors limiting plant root growth. In: Limitations to plant root growth, pp 97-149. Springer

Gilliam FS (2014) The herbaceous layer in forests of eastern North America. Oxford University Press, Oxford

Hill DB, Buck LE (2000) Forest Farming Practices. In: Garrett H, Rietveld W, Fisher R (Eds.), North American agroforestry: an integrated science and practice. American Society of Agronomy

Holmes MA, Matlack GR (2018) Assembling the forest herb community after abandonment from agriculture: long-term successional dynamics differ with land-use history. J Ecol 106(5):2121-2131. https://doi.org/10.1111/1365-2745. 12970

Li TSC, Bedford K, Sholberg P (2000) Improved germination of American ginseng seeds under controlled environments. HortTechnology 10(1):131-135
Li TSC (1995) Asian and American Ginseng-a review. HortTechnology 5(1):27-34

Li TSC, Berard RG (1998) Effects of soil moisture on the growth of American Ginseng (Panax quinquefolium L.). J Ginseng Res 22(2):122-125

Long JA (2019) Interactions: Comprehensive, User-Friendly Toolkit for Probing Interactions. https://cran.r-project.org/ package=interactions

McGraw JB, Furedi MA (2005) Deer browsing and population viability of a forest understory plant. Science 307(5711):920-922. https://doi.org/10.1126/science. 1107036

Mo HS, Park HW, Jang IB, Yu J, Park KC, Hyun DY, Lee EH, Kim KH (2014) Effect of sowing density and number of seeds sown on Panax ginseng C. A. Meyer seedling stands under direct sowing cultivation in blue plastic greenhouse. Korean J Crop Sci 22(6):469-474. https://doi.org/10.7783/ KJMCS.2014.22.6.469

Nadeau I, Olivier A, Simard RR, Coulombe J, Yelle S (1998) Growing American ginseng in maple forests as an alternative land-use system in Québec. Canada Agrofor Syst 44(2):345-353. https://doi.org/10.1023/A:1006275316779

Nadeau I, Simard RR, Olivier A (2003) The impact of lime and organic fertilization on the growth of wild-simulated American ginseng. Can J Plant Sci. https://doi.org/10. 4141/P02-044

Neufeld HS, Young DR (2014) Ecophysiology of the Herbaceous Layer in Temperate Deciduous Forests. In: The Herbaceous Layer in Forests of Eastern North America, 2nd ed.. Oxford University Press. https://doi.org/10.1093/ acprof:osobl/9780199837656.003.0003

Olivier A, Nadeau I, Ouzennou H, Dzaringa JP, Bibang GR (2005) Growth of eight-year-old American ginseng in a red maple forest as influenced by lime and organic fertilizer application. AFTA Conference Proceedings, pp 1-10

OMAFRA-Ontario Ministry of Agriculture and Food (2009) Production recommendations for ginseng (Publication 610)

Ontario Ministry of Agriculture F, RA (2001). Production recommendations for ginseng. Ministry of Agriculture, Food \& Rural Affairs

Parmenter G, Littlejohn R (1998) The effecal of irradiance during leaf development on photoinhibition in Panax ginseng C. A Meyer J Ginseng Res 22(2):102-113

Parmenter G, Littlejohn R (2000) Effect of shade on growth and photosynthesis of Panax ginseng. New Zeal J Crop Hort 28(4):255-269

Peever MJ (2004) The effect of manganese, sodium, calcium, acidity and tree competition on the growth and nutritional status of American ginseng. Master's Thesis, University of Guelph.

Pearcy RW, Pfitsch WA (1995) The Consequences of Sunflecks for Photosynthesis and Growth of Forest Understory Plants. In: Schulze ED, Caldwell MM (Eds.) Ecophysiology of Photosynthesis, pp 343-359. Springer. https://doi. org/10.1007/978-3-642-79354-7_17

Proctor JTA, Palmer JW (2017) Optimal light for greenhouse culture of American ginseng seedlings. J Ginseng Res 41(3):370-372. https://doi.org/10.1016/j.jgr.2016.04.002

Proctor JTA, Shelp BJ (2014) Effect of boron nutrition on American ginseng in field and in nutrient cultures. 
J Ginseng Res 38(1):73-77. https://doi.org/10.1016/j.jgr. 2013.11.002

Proctor JTA, Wang TS, Bailey WG (1988) East Meets West: Cultivation of American Ginseng in China. Hortic Sci 23(6):968-973

R Core Team (2019) R: A Language and Environment for Statistical Computing. R Foundation for Statistical Computing. https://www.R-project.org/

Rackham O (1975) Temperatures of plant communities as measured by pyrometric and other methods. Symposium of the British Ecological Society

Rengel Z (1992) Role of calcium in aluminium toxicity. New Phytol 121(4):499-513

Sanders S, McGraw JB (2005) Hydrastis Canadensis L. (Ranunculaceae) Distribution does not Reflect Response to Microclimate Gradients across a Mesophytic Forest Cove. Plant Ecol 181(2):279-288. https://doi.org/10.1007/ s11258-005-7222-4

Schlag EM, McIntosh MS (2012) RAPD-based assessment of genetic relationships among and within American ginseng (Panax quinquefolius L.) populations and their implications for a future conservation strategy. Gen Res Crop Evol 59(7):1553-1568. https://doi.org/10.1007/s10722-0119784-4

Schluter C, Punja ZK (2002) Genetic diversity among natural and cultivated field populations and seed lots of American Ginseng (Panax quinquefolius L.) in Canada. Int J Plant Sci 163(3):427-439

Shen L, Li XW, Meng XX, Wu J, Tang H, Huang LF, Xiao SM, Xu J, Chen SL (2019) Prediction of the globally ecological suitability of Panax quinquefolius by the geographic information system for global medicinal plants (GMPGIS). Chin J Nat Med 17(7):481-489. https://doi.org/10.1016/ S1875-5364(19)30069-X

Slak, D. (2005). The Establishment and Persistence of American Ginseng (Panax quinquefolius L.) in Maryland Forests. [Thesis]. https://drum.lib.umd.edu/handle/1903/2339

Stoddard JL, Murdoch PS (1991) Catskill mountains. In Acidic deposition and aquatic ecosystems, pp 237-271. Springer.

Stoltz L (1982) Leaf symptoms, yield, and composition of mineral-deficient American ginseng. HortScience 17(5):740-741
Turner JB, McGraw JB (2015) Can putative indicator species predict habitat quality for American ginseng? Ecol Indic 57:110-117. https://doi.org/10.1016/j.ecolind.2015.04.010

US Department of Commerce, N. (n.d.). National Weather Service. NOAA's National Weather Service. Retrieved April 2, 2021, from https://www.weather.gov/

USDA Soil Conservation Service. (1985). Soil Survey of Greene County, New York. U.S. Department of Agriculture.

Venables WN, Ripley BD (2002) Modern Applied Statistics with S (Fourth). Springer. http://www.stats.ox.ac.uk/pub/ MASS4

Wagner A, McGraw JB (2013) Sunfleck effects on physiology, growth, and local demography of American ginseng (Panax quinquefolius L.). For Ecol Manag 291:220-227. https://doi.org/10.1016/j.foreco.2012.11.038

Wei T, Simko V (2017) R package "corrplot": Visualization of a Correlation Matrix (Version 0.84). https://github.com/ taiyun/corrplot

Woodward FI (1981) Shoot extension and water relations of Circaea lutetiana in sunflecks. British Ecological Society Symposium

Wulfsberg M (2019) An Overview of American Ginseng through the Lens of Healing, Conservation and Trade. Lawrence University Honors Projects. https://lux. lawrence.edu/luhp/147

Xing X, Guo S, Fu J (2010) Biodiversity and distribution of endophytic fungi associated with Panax quinquefolium L. cultivated in a forest reserve. Symbiosis 51(2):161-166. https://doi.org/10.1007/s13199-010-0062-6

Young DR, Smith WK (1979) Influence of sunflecks on the temperature and water relations of two subalpine understory congeners. Oecologia 43(2):195-205. https://doi.org/ $10.1007 / \mathrm{BF} 00344770$

Ziadi N, Tran TS (2008) Mehlich 3-extractable elements. Soil Sampl Methods Anal 5:81-88

Publisher's Note Springer Nature remains neutral with regard to jurisdictional claims in published maps and institutional affiliations. 